\title{
Formulation and Evaluation of Phenytoin Sodium Sustained Release Matrix Tablet
}

\author{
Nimmathota Madhavi²*, Beeravelli Sudhakar ${ }^{1}$, P.V.Ravikanth ${ }^{1}$, Kodisana Mohon ${ }^{2}$ and Kolapalli Ramana Murthy ${ }^{1}$
}

${ }^{1}$ Brown's College of Pharmacy, Ammapalem, Khammam-507305, Andhra Pradesh India

${ }^{2}$ A.U.College of Pharmaceutical Sciences, Andhra University, Vishakhapatnam, Andhra Pradesh, India

\begin{abstract}
Epilepsy is a very common disorder, characterized by seizures, which take various forms and result from episodic neuronal discharges, the form of the seizure depending on the part of the brain affected. There is no recognition cause, although it may develop after brain damage, such as trauma, infection or trauma, and other kinds of neurological diseases. Epilepsy is treated mainly with drugs, though brain surgery may be used for severe cases. Sodium channel blockers are generally used in the treatment of seizures, e.g.: phenytoin, carbamazepine, sodium valproate. The aim of this study is to develop sustained release matrix tablet of phenytoin sodium using eudragitRL100, eudragit-RS100, HPMC-E15, ethyl cellulose (N-14), Chitosan and HPMC as release controlling factor and to evaluate drug release parameters as per various release kinetic models. The formulated tablets were also characterized by physical and chemical parameters and results were found in acceptable limits. Different dissolution models were applied to drug release data in order to evaluate release mechanisms and kinetics. Criteria for selecting the most appropriate model were based on linearity (coefficient of correlation). Based on "n" value (0.168) the drug release was follows Fickian diffusion. Also the drug release mechanism was best explained by Higuchi order (correlation value is 0.9063 ) by using this polymer.
\end{abstract}

Keywords: Phenytoin sodium; Sustained release; Eudragit RL100; Eudragit-RS 100; Hydrophilic matrix; Wet granulation technique

\section{Introduction}

Phenytoin sodium is an anti epileptic drug. Phenytoin sodium is related to the barbiturates in chemical structure, but has a fivemembered ring. The therapeutic concentration is required for therapy with recommended doses of $300 \mathrm{mg} /$ day. The therapeutic dose is needed to be maintained for $24 \mathrm{hrs}$. The conventional doses release the entire drug in just few minutes and the therapeutic concentrations are maintained for a short period of time generating a need for administration of another dose. Therefore a sustained release formulation of phenytoin sodium which would release the drug over a time period of $24 \mathrm{hrs}$ is beneficial [1-3].

The concept of sustained release drug delivery has been explored for the delivery of drugs for prolonged period of time for the past few years. Till now there is no sustained release tablet of phenytoin sodium in the market. But phenytoin sodium sustained release capsule (Kapseals) is available. This type of drug delivery has proved to provide a solution to several problems encountered in the repeated administration of such drugs. Utilizing the concept of incorporating drug in to the polymer matrices and extend the drug release for prolonged period of time, an attempt was made to design and evaluate sustained release matrix tablets of phenytoin sodium. The aim of present study is to prepare hydrophilic matrix sustained release tablets containing phenytoin sodium as a model drug and various polymers as hydrophilic matrix to retard drug release. Another objective of this work is to evaluate drug release data using various kinetic models and to determine the mechanism of drug release $[4,5]$.

\section{Materials and Methods}

\section{Materials}

Phenytoin sodium was obtained as a gift sample from (Nakoda Chemicals, Hyderabad) Avicel PH101 (Loba Chemie Pvt. Ltd, Mumbai). HPMC E-15 (Signet Chemical Corporation, Mumbai). Eudragit RS 100 from (Degussa Germany, Mumbai), Eudragit RL 100
(Degussa (Germany), Mumbai) Eudragit RSPO (Degussa Germany, Mumbai), Talc (Qualikems Fine Chemicals Pvt. Ltd, New Delhi).

\section{Preparation of sustained release tablet}

Accurately weighed phenytoin sodium and polymers and passed through sieve \#40 and blend for 10 mins. Prepared granulating solution by dispersing starch in specified quantity of purified water and stirred under a stirrer till a clear solution is formed. Added this binder solution to the previously prepared dry blend of drug and polymer and granulate. Passed the dried granules through sieve $\# 20$ and added lactose, talc and magnesium stearate which was previously passed through sieve \#40 to the dried granules blend. Blended for 5 mins, the granules were sieved by \#22 and \#40.These granules were compressed into tablets by using 16-station rotary tableting machine, using $7 \mathrm{~mm}$ flat, round punches. The composition of the various tablets prepared is given in table1.

\section{Preformulations studies}

Preformulation testing is an investigation of physical and chemical properties of a drug substance alone and when combined with excipients. It is the first step in the rational development of dosage forms. The overall objective of preformulation testing is to generate information useful to the formulation in developing stable and bioavailable dosage forms. The use of preformulation parameters maximizes the chances in formulating an acceptable, safe, efficacious

*Corresponding author: Nimmathota Madhavi, A.U. College of Pharmaceutical Sciences, Andhra University, Visakhapatnam, Andhra Pradesh, India, E-mail: nimmathota.madhavi@gmail.com

Received May 30, 2012; Accepted October 27, 2012; Published October 29 2012

Citation: Madhavi N, Sudhakar B, Ravikanth PV, Mohon K, Ramana Murthy K (2012) Formulation and Evaluation of Phenytoin Sodium Sustained Release Matrix Tablet. J Bioequiv Availab 4: 128-133. doi:10.4172/jbb.1000125

Copyright: (c) 2012 Madhavi N, et al. This is an open-access article distributed under the terms of the Creative Commons Attribution License, which permits unrestricted use, distribution, and reproduction in any medium, provided the original author and source are credited. 
Citation: Madhavi N, Sudhakar B, Ravikanth PV, Mohon K, Ramana Murthy K (2012) Formulation and Evaluation of Phenytoin Sodium Sustained Release Matrix Tablet. J Bioequiv Availab 4: 128-133. doi:10.4172/jbb.1000125

\begin{tabular}{|c|c|c|c|c|c|c|c|c|}
\hline INGREDIENTS & $\mathrm{F} 1$ & $\mathrm{~F} 2$ & F3 & $\mathrm{F} 4$ & F5 & F6 & $\mathrm{F} 7$ & F8 \\
\hline Phenytoin sodium & 100 & 100 & 100 & 100 & 100 & 100 & 100 & 100 \\
\hline Avicel PH101 & - & - & - & 55.15 & 54.3 & 54.2 & - & - \\
\hline Ethyl cellulose N-14 (14 cps) & - & - & - & 4.25 & 8.5 & 7.5 & - & - \\
\hline HPMC & - & - & - & - & - & 5.5 & & - \\
\hline HPMC-E15 & - & - & - & & 5.3 & - & - & - \\
\hline HPMC- K4M & - & - & - & - & - & - & 40 & \\
\hline Chitosan & - & - & - & - & - & - & - & 40 \\
\hline Eudragit RSPO & 30 & - & - & - & - & - & - & - \\
\hline Eudragit RS100 & - & & 30 & 8.5 & - & - & - & - \\
\hline Eudragit RL100 & - & 30 & - & - & - & - & - & \\
\hline Lactose & 1.5 & 2 & 6.5 & & - & - & 1.6 & 1.6 \\
\hline Mg.stearate & 1.5 & 1.8 & 2 & 1.7 & 1.7 & 1.5 & 1.5 & 1.5 \\
\hline Talc & 0.6 & 5.5 & 7 & & - & - & 0.6 & 0.6 \\
\hline Colloidal silicone dioxide & - & & & 0.4 & 0.6 & 0.8 & - & - \\
\hline Starch & $5 \%$ & $5 \%$ & $5 \%$ & - & - & - & - & - \\
\hline Purified water & q.s & q.s & q.s & q.s & q.s & q.s & q.s & q.s \\
\hline SLS & 7.5 & 7.5 & 6.5 & 3.25 & 6.5 & 7.5 & 3.25 & 6.5 \\
\hline
\end{tabular}

$\mathrm{F} 1, \mathrm{~F} 2$ and $\mathrm{F} 3$ formulations contain processed starch in percentage of $5 \%$.

$\mathrm{F} 5$ and $\mathrm{F} 6$ formulations contain colloidal silicon dioxide in the percentage of $0.5-1 \%$.

F5 and F6 formulations contain Avicel PH101 in the percentage of 53-55\%.

Table 1: Tablet Formulations

and stable product. We carried out the solubility, angle of repose, bulk density, tapped density and sieve analysis. All preformulation studies were carried out by using USP standards.

\section{Solubility studies}

The solubility of phenytoin sodium was determined by dissolving the highest unit dose of the drug in $500 \mathrm{~mL}$ of buffer adjusted between $\mathrm{pH} 1.0$ and 8.0. For this purpose $0.1 \mathrm{~N} \mathrm{HCl}, \mathrm{pH} 6.8$ buffer and purified water were used. Highest dose of the drug i.e., $1000 \mathrm{mg}$ was dissolved in $500 \mathrm{~mL}$ of medium and was kept untouched for 6 hrs. Later on the insoluble drug was filtered off and the solution was analyzed by UV technique to find out the solubility. Based on the solubility calculated the (Dose/Solubility) ratios were calculated [6].

\section{Dose calculations \& construction of theoretical release profile}

The total dose of phenytoin sodium for twice-daily SR formulation was calculated by Michaelis Menton equation using available pharmacokinetic data.

Calculation of loading dose (LD):

$\mathrm{LD}=\mathrm{V}_{\mathrm{d}}{ }^{\star} \mathrm{Cp} / \mathrm{S}^{*} \mathrm{~F}$

$\mathrm{LD}=49^{\star} 18 / 1^{\star} 0.95$

$\mathrm{LD}=928.42 \mathrm{mg}$ of Phenytoin sodium.

Oral loading dosing should be given in 3 to 4 divided doses.

Calculation of maintenance dose (MD):

$\mathrm{MD}=\operatorname{Vmax}^{\star} \mathrm{Css} / \mathrm{S}^{\star} \mathrm{F}\left(\mathrm{K}_{\mathrm{m}}+\mathrm{C}_{\mathrm{ss}}\right)$

$\mathrm{MD}=7^{\star} 15 / 1^{\star} 0.95(5.4+15)=5.41 \mathrm{mg} / \mathrm{Kg}$.

For steady state plasma concentration, total dose per day required

$$
\begin{aligned}
& \mathrm{D}=\mathrm{V}_{\mathrm{m}}{ }^{\star} \mathrm{C}_{\mathrm{ss}}{ }^{\star} \tau /\left(\mathrm{K}_{\mathrm{m}}+\mathrm{C}_{\mathrm{ss}}\right) \mathrm{S}^{\star} \mathrm{F} \\
& \mathrm{D}=700^{\star} 15^{\star} 1 /(6.8+15) 1^{\star} 0.95 \\
& \mathrm{D}=10500 / 20.713 \\
& \mathrm{D}=507.00 \mathrm{mg} / \text { day. }
\end{aligned}
$$

The dose is given in 2 or 3 divided doses, thus the administered dose is $500 \mathrm{mg}$ twice a day.

\section{Evaluation of tablet}

The finished products were evaluated as per the procedures given in USP I which recommends the following tests for sustained release tablets.

Weight variation test: To study weight variation, 20 tablets of each formulation were weighed using an electronic balance (Mettler Toledo, Basel, Switzerland). (Then average weight is calculated), each tablet was weighed individually and weight was noted. The weights of individual tablets were compared with the average weight already calculated. Mean and SD were calculated.

Content uniformity: Five tablets were weighed individually, then placed in a mortar and powdered with a pestle. An amount equivalent to $100 \mathrm{mg}$ was extracted with $100 \mathrm{ml} \mathrm{pH} 6.8$ phosphate buffer, and sonicated for 15 minutes. The solution was filtered through a filter paper $(0.22 \mu \mathrm{m}$ pore size $)$, properly diluted with $\mathrm{pH} 6.8$ phosphate buffer, and then the drug content was measured as previously mentioned.

Friability: For each formulation, 6 tablets were weighed. The tablets were placed in a friabilator (Roche friabilator) and subjected to 100 rotations in 4 minutes at $25 \mathrm{rpm}$. The tablets were then deducted and reweighed. The friability was calculated as the percentage weight loss [7-9]. 
Hardness test: For each formulation, the hardness of 6 tablets was determined using a hardness tester (Monsanto). Hardness values were reported in kilograms $(\mathrm{kg})$. Mean and SD were calculated.

In vitro release studies: In vitro release studies of phenytoin sodium sustained release tablets were monitored. The release experiments were performed in a $900-\mathrm{mL}$ dissolution medium of hydrochloric acid $\mathrm{pH}$ 1.2 for the first 2 hours and then replaced with the same volume of a phosphate buffer solution $\mathrm{pH} 6.8 \mathrm{kept}$ at $37^{\circ} \mathrm{C} \pm 0.5^{\circ} \mathrm{C}$ and stirred at $100 \mathrm{rpm}$, using USP-I basket dissolution apparatus I(perfect sink conditions). 5 -mL sample was withdrawn through a $0.45 \mu \mathrm{m}$ filter and replaced with another $5 \mathrm{ml}$ of a suitable fresh dissolution medium at predetermined intervals up to 24 hours. The amount of the drug was determined by UV-spectroscopy at $258 \mathrm{~nm}$.

\section{Kinetic data analysis}

To analyze the in vitro release data various kinetic models were used to describe the release kinetics [2].

The following plots were made (Figure 1):

- Cumulative \% drug release vs. time (Zero-order kinetic model);

- Log cumulative of $\%$ drug remaining vs. time (First-order kinetic model);

- Cumulative \% drug release vs. square root of time (Higuchi model) ;

- Log cumulative $\%$ drug release vs. Log time (Korsmeyer model).

\section{Mechanism of drug release}

Cooper J [5] derived a simple relationship which described drug release from a polymeric system. To find out the mechanism of drug release, first $60 \%$ drug release data was fitted in Korsmeyer-Peppas model:

$$
\mathrm{M}_{\mathrm{t}} / \mathrm{M}_{\infty}=\mathrm{K} \mathrm{t^{ \textrm {n } }}
$$

Where $M_{t} / M_{\infty}$ is fraction of drug released at time $t, K$ is the rate constant and $\mathrm{n}$ is the release exponent. The $\mathrm{n}$ value is used to characterize different release mechanisms as given in table 3 for cylindrical shaped matrices.

\section{Result and Discussion \\ Preformulations studies}

The pure phenytoin sodium and granules of different formulations were evaluated for angle of repose, bulk density, tap density, Carr's index and sieve analysis. The phenytoin sodium and the formulated granules were characterized with respect to angle of repose [10-12]. Angle of repose of phenytoin sodium was found to be $33.2^{\circ}$ thus indicating that the flow properties were poor (passable). For the granules of all the formulated batches, the angle of repose was found to be in the range of $25^{\circ}$ to $38^{\circ}$, thus indicating that the flow properties were fair - poor (passable). Therefore it was decided to include $1.0 \%$ to $1.2 \%$ of talc as a glidant.
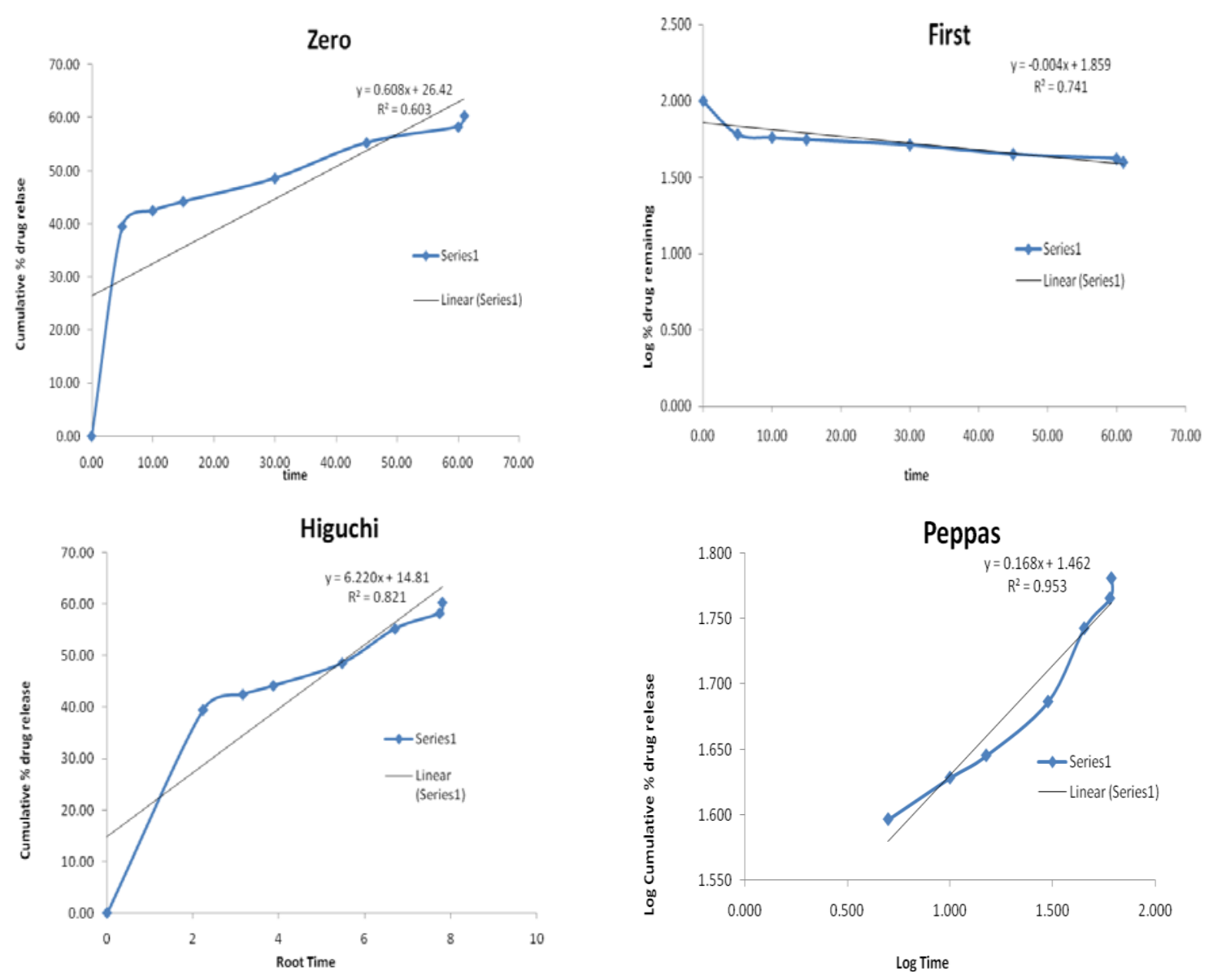

Figure 1: Release fitting graphs. 
Citation: Madhavi N, Sudhakar B, Ravikanth PV, Mohon K, Ramana Murthy K (2012) Formulation and Evaluation of Phenytoin Sodium Sustained Release Matrix Tablet. J Bioequiv Availab 4: 128-133. doi:10.4172/jbb.1000125

The phenytoin sodium and the formulated granules were characterized with respect to bulk and tapped density. The Carr's index of phenytoin sodium found to be 11.6. Thus indicating that the flow properties were excellent. For the granules of all the formulated batches, the Carr's index was found to be in the range of 5-55, thus indicating that the flow properties were very poor. Therefore it was decided to include $1.0 \%$ to $1.2 \%$ of Talc as a Glidant (Table 2) [13-17].

\section{Particle size analysis of phenytoin sodium}

The phenytoin sodium percentage retained was found to be approximately $150 \mu-200 \mu$. Particles in this size range pose no serious problems like charge development. Therefore it was decided to use the phenytoin sodium as it can be used without any further processing (like milling to decrease the particle size or adsorption or removal of fine to decrease cohesive forces) (Table 3) [18].

\section{Solubility studies}

Based on the result in table 4 and the drug phenytoin sodium was determined to be slightly soluble and very slightly soluble, in order to increase its solubility, sodium lauryl sulphate, a surfactant was decided to be included in all formulations (Table 4 and 5).

\section{Physical properties of the matrix tablets}

All the formulations of tablets were subjected to various evaluation tests, such as friability, hardness, average weight, drug content, and in vitro dissolution. In a weight variation test, the average percentage deviation of all tablet formulations was found to be within the limit of IP, and hence all formulations passed the test for uniformity of weight as per official requirements [19].

Good uniformity was found among the different batches of the tablets, and the percentage of drug content was more than $101.22 \pm 0.88$ (F4). The formulation F4 showed a comparatively high hardness value of $9.53 \pm 0.75 \mathrm{~kg} / \mathrm{sqcm}$. Tablet hardness is not an absolute indicator of strength. Another measure of tablet strength is friability. Conventional compressed tablets that lose less than $1 \%$ of their weight are generally considered acceptable (Table 6) [20,21].

\section{Dissolution profiles}

The in vitro drug release characteristics were studied $(\mathrm{n}=3)$ in $0.01 \mathrm{~N}$ hydrochloric acid and Phosphate buffer 6.8 Ph mediums for a period of $24 \mathrm{hrs}$ using USP-I basket dissolution apparatus. The initial four formulations (F1, F2, F3 and F4) of phenytoin sodium SR tablets were formulated with different types of Eudragit polymers (Eudragit RSPO, Eudragit RS100, and Eudragit RL100). Eudragit RL100 and Eudragit RS100 are insoluble in aqueous media but they are permeable and both have $\mathrm{pH}$-independent release profiles. The permeability of Eudragit RS100 and RL100 in aqueous media is due to the presence of quaternary ammonium groups in their structure; Eudragit RL100 has a greater proportion of these groups and as such is more permeable than Eudragit RS100. The combinations of these polymers in different proportions provide varied sustained release profiles. Therefore the subsequent batches were planned with different concentrations of

\begin{tabular}{|c|c|c|c|c|}
\hline Batch no. & Angle of Repose $\left({ }^{\circ}\right)$ & Bulk density $(\mathbf{g} / \mathbf{m L})$ & Tapped density (g/mL) & Carr's Index (\%) \\
\hline API & 33.2 & 0.76 & 0.86 & 11.6 \\
\hline F1 & 30.5 & 0.73 & 0.85 & 14.1 \\
\hline F2 & 32.6 & 0.513 & 0.647 & 20.7 \\
\hline F3 & 35.7 & 0.752 & 0.796 & 17.5 \\
\hline F4 & 33.8 & 0.555 & 0.673 & 19.3 \\
\hline F5 & 38.7 & 0.597 & 0.740 & 5.63 \\
\hline F6 & 28.6 & 0.620 & 0.657 & 34.6 \\
\hline F8 & 36.4 & 0.465 & 0.712 & 5.69 \\
\hline
\end{tabular}

Table 2: Preformulations Studies.

\begin{tabular}{|c|c|c|c|c|}
\hline Sieve number & Microns $(\boldsymbol{\mu})$ & Wt. of sieve $(\mathbf{A})$ & Final weight (B) & \% retained (B-A) \\
\hline 20 & 200 & 368.2 & 393.4 & 25.2 \\
\hline 30 & 212 & 362.3 & 372.6 & 20.3 \\
\hline 40 & 150 & 361.3 & 382.6 & 21.4 \\
\hline 60 & 125 & 355.2 & 375.6 & 20.4 \\
\hline 80 & 90 & 350.6 & 357.8 & 6.5 \\
\hline 100 & 75 & 350.6 & 355.6 & \\
\hline
\end{tabular}

Table 3: Particle Size Analysis of Phenytoin Sodium.

\begin{tabular}{|c|c|c|c|c|}
\hline S.No. & Medium & Solubility (mg/mL) & D/S ratio(mL) & Inference \\
\hline 1 & Purified water & 1.36 & 735.29 & Slightly soluble \\
\hline 2 & $0.1 \mathrm{~N} \mathrm{NaoH}$ & 0.833 & 1200.48 & Very slightly soluble \\
\hline 3 & pH 6.8 buffer & 1.25 & 800 & Slightly soluble \\
\hline 4 & pH 7.4 buffer & 0.90 & 1111.11 & Very slightly soluble \\
\hline 5 & Ethanol & 0.85 & 1176.47 & Very slightly soluble \\
\hline 6 & Isopropyl alcohol & 0.76 & 1315.78 & Very slightly soluble \\
\hline
\end{tabular}

Table 4: Solubility studies. 
Citation: Madhavi N, Sudhakar B, Ravikanth PV, Mohon K, Ramana Murthy K (2012) Formulation and Evaluation of Phenytoin Sodium Sustained Release Matrix Tablet. J Bioequiv Availab 4: 128-133. doi:10.4172/jbb.1000125

these polymers. However satisfactory results were not obtained for these polymers and it was decided to proceed with other polymers which would effectively sustained the release of drug. The effect of these polymers on the release of phenytoin sodium is shown in the following table 7.

The F5 batch was formulated with HPMC-E15 and ethyl cellulose (N-14), F6 batch was formulated with HPMC and ethyl cellulose (N-14). F6 formulation is showing better release from the phenytoin sodium tablet. So F6 formulation is decided as optimized formulation .The effect of these polymers on the release of Phenytoin sodium from the tablets [22].

The F7 batch was formulated with HPMC-K4M .The F8 batch was formulated with Chitosan. Chitosan is one of the most suitable matrix type of sustained release polymer. The effect of these polymers on the release of phenytoin sodium from the tablets is shown in the following figure 2 .

\section{Release mechanism}

Based on the " $n$ " value of 0.168 obtained for F6 formulation, the drug release was found to follow Fickian diffusion. Also, the drug release mechanism was best explained by Higuchi's equation, as the plots showed the highest correlation $0.9063, \mathrm{r}^{2}$ value is 0.821 . Drug release kinetics of this formulation corresponds best to Higuchi's model (Table 8) [23,24].

\section{Conclusion}

The aim of the present study was to develop a sustained release tablet of phenytoin sodium due to narrow therapeutic window of phenytoin sodium to reduce dosing frequency. An efficient sustained release formulation of phenytoin sodium could not be designed as sustained release tablets, because up to $12 \mathrm{hrs}$ it releases $60 \%$ of the drug. So it required some extent of work for desired sustained release. In this study the optimized formulation (F6) was developed by using hydroxy propyl methyl cellulose as a polymer base. Regulated drug release in Higuchi order manner was attained by using this polymer.

\begin{tabular}{|c|c|}
\hline \multicolumn{1}{|c|}{ Concentration } & absorbance \\
\hline 0 & 0 \\
\hline 0.02 & 0.177 \\
\hline 0.04 & 0.340 \\
\hline 0.06 & 0.499 \\
\hline 0.08 & 0.655 \\
\hline 0.10 & 0.820 \\
\hline
\end{tabular}

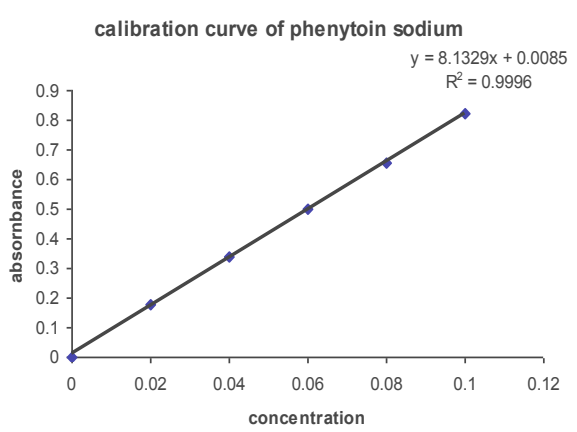

Table 5: calibration curve of phenytoin sodium.

\begin{tabular}{|c|c|c|c|c|}
\hline Batch & Friability (\%) & $\begin{array}{l}\text { Hardness } \\
(\mathrm{Kg} / \mathrm{Sqcm})\end{array}$ & $\begin{array}{c}\text { Average uniformity of weight } \\
(\mathrm{mg})\end{array}$ & Drug Content (\%) \\
\hline $\mathrm{F} 1$ & 0.21 & $8.56 \pm 0.31$ & $766.8 \pm 2.48$ & $98.25 \pm 1.37$ \\
\hline $\mathrm{F} 2$ & 0.17 & $5.34 \pm 0.71$ & $765 \pm 2.54$ & $95.28 \pm 0.80$ \\
\hline F3 & 0.19 & $7.53 \pm 0.25$ & $768.6 \pm 2.41$ & $99.12 \pm 2.47$ \\
\hline $\mathrm{F} 4$ & 0.13 & $9.53 \pm 0.75$ & $770.8 \pm 1.64$ & $101.22 \pm 0.88$ \\
\hline F5 & 0.22 & $7.63 \pm 0.84$ & $767.6 \pm 2.14$ & $100.24 \pm 1.25$ \\
\hline F6 & 0.16 & $7.13 \pm 0.25$ & $769.0 \pm 2.43$ & $95.35 \pm 1.14$ \\
\hline $\mathrm{F} 7$ & 0.18 & $8.24 \pm 0.61$ & $770.5 \pm 1.80$ & $96.34 \pm 2.18$ \\
\hline
\end{tabular}

Table 6: Physical properties of the Matrix Tablets.

\begin{tabular}{|c|c|c|c|c|c|c|c|c|}
\hline Batch & Time & $30 \mathrm{mini}$ & $1 \mathrm{hr}$ & $2 \mathrm{hrs}$ & $4 \mathrm{hrs}$ & $8 \mathrm{hrs}$ & $12 \mathrm{hrs}$ & $24 \mathrm{hrs}$ \\
\hline $\mathrm{F} 1$ & 0 & $22.3 \pm 2.6$ & $26.1 \pm 2.9$ & $35.3 \pm 1.8$ & $47.5 \pm 2.2$ & $48.2 \pm 1.9$ & $48.4 \pm 2.4$ & $48.3 \pm 2.4$ \\
\hline $\mathrm{F} 2$ & 0 & $27.9 \pm 2.1$ & $36.9 \pm 1.4$ & $45.9 \pm 1.9$ & $48.1 \pm 2.2$ & $48.2 \pm 1.7$ & $49.7 \pm 1.7$ & $49.3 \pm 1.7$ \\
\hline F3 & 0 & $32.7 \pm 1.6$ & $35.2 \pm 2.1$ & $39.7 \pm 2.3$ & $43.9 \pm 1.9$ & $45.5 \pm 2.1$ & $47.2 \pm 2.2$ & $47.3 \pm 2.2$ \\
\hline $\mathrm{F} 4$ & 0 & $38.2 \pm 2.1$ & $42.3 \pm 2.3$ & $45.3 \pm 1.6$ & $46.4 \pm 2.4$ & $49.7 \pm 1.9$ & $50.3 \pm 1.8$ & $52.3 \pm 1.8$ \\
\hline $\mathrm{F} 5$ & 0 & $26.3 \pm 1.8$ & $28.3 \pm 2.1$ & $35.5 \pm 1.6$ & $38.6 \pm 1.4$ & $39.3 \pm 1.7$ & $40.7 \pm 1.7$ & $40.7 \pm 1.7$ \\
\hline F6 & 0 & $39.5 \pm 2.1$ & $42.9 \pm 1.8$ & $44.2 \pm 2.2$ & $48.6 \pm 2.3$ & $55.3 \pm 1.9$ & $58.3 \pm 1.6$ & $60.4 \pm 1.7$ \\
\hline $\mathrm{F} 7$ & 0 & $35.5 \pm 2.4$ & $37.9 \pm 2.1$ & $40.2 \pm 1.8$ & $46.8 \pm 1.6$ & $47.1 \pm 1.7$ & $49.9 \pm 1.9$ & $52.2 \pm 1.7$ \\
\hline F8 & 0 & $30.2 \pm 1.8$ & $42.2 \pm 2.1$ & $45.6 \pm 1.9$ & $49.3 \pm 2.4$ & $51.5 \pm 2.1$ & $53.6 \pm 1.8$ & $55.8 \pm 2.3$ \\
\hline
\end{tabular}

Table 7: Dissolution profiles of formulations. 
Citation: Madhavi N, Sudhakar B, Ravikanth PV, Mohon K, Ramana Murthy K (2012) Formulation and Evaluation of Phenytoin Sodium Sustained Release Matrix Tablet. J Bioequiv Availab 4: 128-133. doi:10.4172/jbb.1000125

\begin{tabular}{|c|c|c|c|c|c|c|c|c|c|}
\hline Batch & Zero order & & First order & & Higuchi & & Peppas & & \\
\hline & $\mathrm{R}^{2}$ & correlation & $\mathrm{R}^{2}$ & correlation & $\mathrm{R}^{2}$ & Correlation & $\mathrm{R}^{2}$ & $\mathrm{n}$ & Correlation \\
\hline F1 & 0.520 & 0.7215 & 0.570 & 0.7555 & 0.768 & 0.8767 & 0.771 & 0.221 & 0.8782 \\
\hline $\mathrm{F} 2$ & 0.529 & 0.7277 & 0.595 & 0.7720 & 0.779 & 0.7828 & 0.827 & 0.203 & 0.9094 \\
\hline F3 & 0.527 & 0.7263 & 0.613 & 0.7832 & 0.773 & 0.8792 & 0.981 & 0.151 & 0.9908 \\
\hline F4 & 0.451 & 0.6720 & 0.537 & 0.7333 & 0.701 & 0.8373 & 0.965 & 0.111 & 0.9826 \\
\hline F5 & 0.550 & 0.7419 & 0.614 & 0.7839 & 0.794 & 0.8913 & 0.918 & 0.179 & 0.9584 \\
\hline F6 & 0.603 & 0.7692 & 0.741 & 0.8612 & 0.821 & 0.9063 & 0.953 & 0.168 & 0.9766 \\
\hline F7 & 0.543 & 0.7371 & 0.644 & 0.8028 & 0.780 & 0.8835 & 0.971 & 0.150 & 0.9856 \\
\hline F8 & 0.576 & 0.7590 & 0.677 & 0.8230 & 0.814 & 0.9026 & 0.894 & 0.204 & 0.9456 \\
\hline
\end{tabular}

$\mathrm{R}^{2}=$ Corrélation coefficient; $\mathrm{n}=$ Diffusion Al exponent

Table 8: Release kinetic data
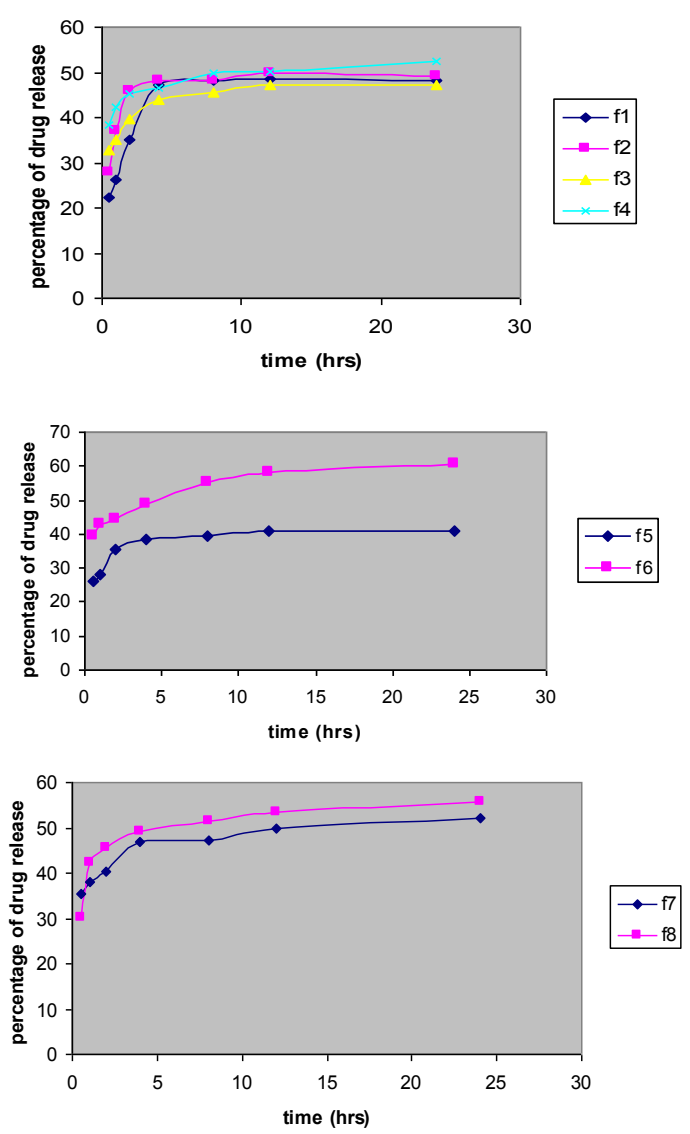

Figure 2: Percentage release graphs.

\section{References}

1. Burstein AH, Cox DS, Mistry B, Eddington ND (1999) Phenytoin pharmacokinetics following oral administration of phenytoin suspension and fosphenytoin solution to rats. Epilepsy Res 34: 129-133.

2. Varshosaz J, Tavakoli N, Kheirolahi F (2006) Use of hydrophilic natural gums in formulation of sustained-release matrix tablets of tramadol hydrochloride. AAPS PharmSciTech 7: E24.

3. Raja ST, Palanichamy S, Shanmuganathan S, Tamilvanan S, Thanga TA (2009) Formulation and Evaluation of Theophylline Controlled Release Matrix Tablets using Guar gum. Ars Pharm 51: 28-38

4. Deshmukh VN, Singh SP, Sakarkar DM (2009) Formulation and Evaluation of Sustained Release Metoprolol Succinate Tablet using Hydrophilic gums as Release modifiers. Int J Pharm Tech Res 1: 159-163.

5. Cooper J, Gunn C (1986) Powder flow and compaction. Tutorial Pharmacy, New Delhi, CBS Publishers and Distributors, India.
6. Shah, Shelat (2010) Design and Evaluation of Matrix Tablets Containing a Natural Polysaccharide as a Carrier to Optimize Active Drug's (Nsaid) Absorption Profile for Bedtime Administration (Chronotherapeutic Delivery). International Journal of Pharmaceutical Res 2: 52-61.

7. Basak SC, Kartikeyan J, Bhusan B (2010) Design, In vitro Evaluation and Release Rate Kinetics of Matrix Type Sustained Release Tablet Containing Aceclofenac. The Internet Journal of Pharmacology 8: 5-11.

8. Khemariya $P$, Jain AK, Bhargava M, Singhai SKS, Goswami R, et al. (2010) Preparation and In-Vitro Evaluation of Sustained-Release Matrix Tablets of Diltiazem. International journal of advances in pharmaceutical sciences 1: 267273.

9. Ali MDS, Singh S, Kumar A, Singh S, Ansari MDT, et al. (2010) Preparation and invitro evaluation of sustained release matrix tablets of Phenytoin sodium using natural polymers. Int J Pharm Pharm Sci 2: 174-179.

10. Savaşer A, Ozkan Y, Işimer A (2005) Preparation and in vitro evaluation of sustained release tablet formulations of diclofenac sodium. Farmaco 60: 171177

11. Jachowicz R (1987) Dissolution rates of partially water soluble drugs from solid dispersion systems. II. Phenytoin. Inter J Pharm 35: 7-12.

12. Batsami SM, Groves MJ (1978) Some factors influencing the in vitro release of phenytoin from formulations. Int J Pharm 1: 151-164.

13. Siahi MR, Barzegar-Jalali M, Monajjemzadeh F, Ghaffari F, Azarmi S (2005) Design and evaluation of 1- and 3-layer matrices of verapamil hydrochloride for sustaining its release. AAPS PharmSciTech 6: E626-632.

14. Avachat A, Kotwal V (2007) Design and evaluation of matrix-based controlled release tablets of diclofenac sodium and chondroitin sulphate. AAPS PharmSciTech 8: E88.

15. Abdelkader A, Abdalla OY, Salem H (2007) Formulation of Controlled-Release Baclofen Matrix Tablets II: Influence Some Hydrophobic Polymers on the Release Rate and In Vitro Evaluation. AAPS PharmSciTech 9: 675-680.

16. Barzegar-Jalali M, Siahi Shadbad MR, Azarmi S, Barzegar-Jalali A, Mohammad $\mathrm{G}$, et al. (2007) Study on the release of acetazolamide from matrices containing tragacanth and acacia gums. J of Faculty of Pharmacy, Tabriz University of Medical Sciences.

17. Jannin V Pochard E, Chambin O (2006) Influence of poloxamers on the dissolution performance and stability of controlled-release formulations containing Precirol ATO 5. Int J Pharm 309: 6-15.

18. Liew CV, Chan LW, Ching AL, Heng PW (2006) Evaluation of sodium alginate as drug release modifier in matrix tablets. Int J Pharm 309: 25-37.

19. Aceves JM, Cruz R, Hernandez E (2000) Preparation and characterization of Furosemide-Eudragit controlled release systems. Int J Pharm 195: 45-53.

20. www.uspto.gov, United States Patent 6274168.

21. www.uspto.gov, United States Patent 6274168B1.

22. www.uspto.gov, United States Patent 20060222713.

23. FDA guidance on "Dissolution Testing of Immediate Release Solid Oral Dosage Forms".

24. Salehifar E, Zohrabi M, Eshghi S, Saeedi M, Ebrahimi P (2009) Differen pharmacokinetic parameters of phenytoin in Iranian Outpatients: Need to optimize the current dosage administration, International Journal of Pharmaceutical Research 8: 37-45. 